\title{
Educational information systems: Problems of the small educational organisation
}

\author{
John G Hedberg, Barry Harper \\ University of Wollongong \\ Deborah Bloch \\ Baruch College \\ City University of New York
}

\begin{abstract}
This paper describes the issues surrounding the provision of information systems to small educational organisations, in particular, the concerns which need to be considered when generating a comprehensive strategy for the implementation of an educational integrated information system. The paper reviews both information systems strategy research and innovations in educational technology, and reports on two studies of the problems in information systems strategy of educational professionals. In the major study, survey responses from 432 high schools were analysed to examine the relative use of microcomputer school information systems for efficiency of routine functions versus effective decision-making defined as greater use of information by school personnel. Schools showed significantly greater use of the systems for more efficient processing of routine tasks. However, operational factors related to the use of the systems as informing tools for more effective decision-making were able to be singled out, and relationships among measures of efficiency, effectiveness, decision-making and operational factors were identified. The article concludes with implications for institutional practice, related research and professional preparation of educational administrators.
\end{abstract}

\section{Information Systems for Small Organisations}

The individual primary or high school and similar small educational organisations face unique information needs. The development of effective information systems must occur within budget constraints, and often with little professional assistance. The changing technologies of information 
systems and the particular needs of this type of organisation to deliver its products - curriculum, instruction and testing - and integrate them into its routine administrative and educational operations pose unique challenges. Their uniqueness is defined by the largely flat type of organisation, the lack of specialisation within the small administrative structure, and fluid nature of many of the school's educational activities.

Caputo (1988) reviewed the general problem of information systems in the humans services area. He raised three concerns in applying information technology strategy to this type of organisation: first, the problem of creating measurable units for human services inputs and outputs and relating their impact to the client of the organisation; second, the collection of information across boundaries is often difficult because of the political and "territorial" nature of the sub-units in such organisations; and third, that while these types of organisations can buy technology to implement some form of computerisation of data, no existing plan has moved beyond the integration of data into a total information systems strategy for all data in the organisation. This last point can be clarified through the example of the types of IT technologies typically found in the small educational organisation, most are discrete units of equipment, usually based on a classroom, office or library, with no plan for integration or networking beyond the geography of the room and no integrated information systems solution for the whole organisation.

Sirotnik and Burnstein (1987) in an early discussion about the problems of a school-based information system suggested that the standard structure of identifying needs and objectives covering steps such as:

1. Review the current school system to identify the extent it meets current and anticipated needs.

2. Conduct an information needs analysis, identifying what teachers and administrators view as useful information.

3. Identify the problems which any information system could address.

4. Develop plans to collect additional data.

5. Select appropriate technologies to implement the system. Appropriate hardware and software, identify expertise of potential users, consultant support required and the range of functions.

6. Create prototype analyses and reporting formats to demonstrate the capabilities of the information system which can support the information needs of the school staff.

7. Initiation phase, focus on the time consuming clerical activities.

8. Expansion phase, growth in the understanding of the shift from computer management to data management.

Telem (1989) has also raised the problems of the small educational organisation and its inability to respond to information systems planning. He identified that the major source of difficulty was the lack of specialised 
professional skills in systems design and implementation and the highly fluid nature of the services and organisational structure. Compared with the industry or business organisation, there are many open-ended possibilities involved with the high order products in which the information system might be involved. Even compared with the larger educational organisation, there are no specialised groups within the school which are charged with the provision, planning and maintenance of the information systems resources. This lack of on-site expertise poses particular challenges and difficulties for the small educational unit. Telem compared educational information systems development with the standard construction proposed by Nolan (1979). He suggested that the often considered six phases should be condensed into three: Initiation, Contagion and Maturity. Only at the last, maturity, does the school achieve integrated information systems where data can be combined, transferred from one part of the operation to any other, and even moved directly outside the school to parents, regional administrators and the like. The key feature is the production intersystem integrative information to enable the individual to improve their decision support systems and group decision making. He identified the following growth features within the small organisations development (see Table 1)

Table 1: Growth features within small organisations development (after Telem, 1989)

\section{Growth features}

No of computerised systems

No of microcomputers / terminals

Communications network Intersystems integration Clerically oriented usage Information usage for DSS

Automated office tools use MIS and automated office tools integration Information integration

$\begin{array}{ccc}\text { Initiation } & \text { Growth Stages } \\ \text { Few } & \text { Many } & \text { Maturity } \\ \text { Men } & \text { "All" }\end{array}$

One to few Few to many In all necessary

\begin{tabular}{|c|c|}
\hline None & Partial \\
\hline None & Large \\
\hline Most & Less \\
\hline $\begin{array}{l}\text { Local, if at } \\
\text { all }\end{array}$ & Little \\
\hline Few & Many \\
\hline None & $\begin{array}{l}\text { Low to } \\
\text { medium }\end{array}$ \\
\hline From none & From medium \\
\hline
\end{tabular}

Integrative information systems are dependent on the growth in sophistication of three elements: the information systems tools - from communication, through a database management system through to artificial intelligent and performance support systems; the approach to information - from data in programs through file management to a database approach and query languages; and the type of user - from dependent to independent. All three elements must be present to achieve an integrated information system. 


\section{The school as a small educational organisation}

The microcomputers massive penetration into the data processing world has opened up new opportunities and strongly pushed the use of this type of facility into small organisations such as schools. Unfortunately, in many cases, management information system initiation, growth, and integration in these small organisations is unorganised, disorderly and lacks long term planning for MIS introduction and development. This leads to situations where computers do operate, but their improper use precludes any contribution toward the ultimate mission of the information system: improvement of the information workers performance, and thus information flow, through the application of information technology.

March (1987) has examined the characteristics of a school as a small organisation. He has reported that schools are small in size and simple in structure and devote a relatively small amount of its resources to administrative expenses. Their hierarchy is characteristically quite flat and uncomplicated. The degree of specialisation within the school's administration is modest and school administrators in general cannot be considered professionalised. Technologies in the school are unclear, goals ambiguous and participation fluid. Studies have shown that this situation is compounded by poor or no communication between different school officials, decision-making based on incomplete or non-existent information, poor or no control and monitoring of different school activities and partially updated data and data duplication. Schools typically lack a data processing unit - although the schools managers frequently lack understanding of and training in MIS, these very persons are delegated the responsibility for planning and executing hardware and software acquisition, installation, maintenance and operation of the system within the organisation.

The process of attaining a 'maturity' level in information systems development requires effective planning. Many small organisations are now going through this process as the value of efficiency in information handling becomes more apparent to the success of small organisations. As an example the NSW Department of School Education has taken steps to try to address the reported lack of management information systems in schools as part of its overall plan for what it terms "Schools Renewal". The Scott report (1990)was commissioned to advise the then Minister of Education on the remodelling of the Department of School Education (DSE) Management system. The brief also included advise on the management information systems of schools, as small organisations, with the report coming up with a number of key recommendations on how this could be achieved. 
One of the management reviews major recommendations was the substantial upgrading and maintenance of the Department's management systems in line with advances in technology. It was proposed that the high initial capital costs would be offset by savings from improved efficiency which will increase substantially over time. The key features of this new approach to logistics in the MIS of the DSE would be

1. the devolution of decision making and hence administrative work

2. plans to upgrade equipment standards and to innovate in

communications, information flows and office systems and

3. making rational choice between use of in-house departmental

resources, other government resources, and private sector resources - to achieve the most efficient and effective overall results in terms of office accommodation, purchases, communications and administrative services in general

At the same time the introduction of the MIS initiative of the OASIS system was being trialed in schools and it was recommended that this system form the basis of a school based MIS. The system has a number of administrative modules which can be used for the general working of the school. They currently include Student and Staff, School Information and System Management as well as OASIS Word. Two further modules on School Finance and an OASIS database are to be introduced to schools under certain criteria. If the school qualifies, they may also have installed a library management system.

An overall plan for the integration of data into a total information systems strategy for all data in the organisation at the school level has not been developed, but a number of regions have developed Managements Plans as part of their Regional Strategic Plans. These type of plans at least go part of the way in alleviating Caputo's (1988) concern about the lack of integrated planning, but nevertheless, this system has been introduced into schools without a clear specification of its role in the overall school management information systems goals.

The system has however been supported by staff development programs. The available support has concentrated on the technical nature of OASIS system, not on the management and overall integration into school organisation. Training has been exclusively for systems operators and Clerical heads of school support staff but school principals have been invited to attend many of the training programs with their administrative staff. The system comes with a number of training days costed in and extra days can be funded at the school level. Regional support has been set up to train staff and technically support the hardware. The main emphasis has been on technical support for the software and hardware, not on developing innovative and proficient use of the system or on integration across the school system. 


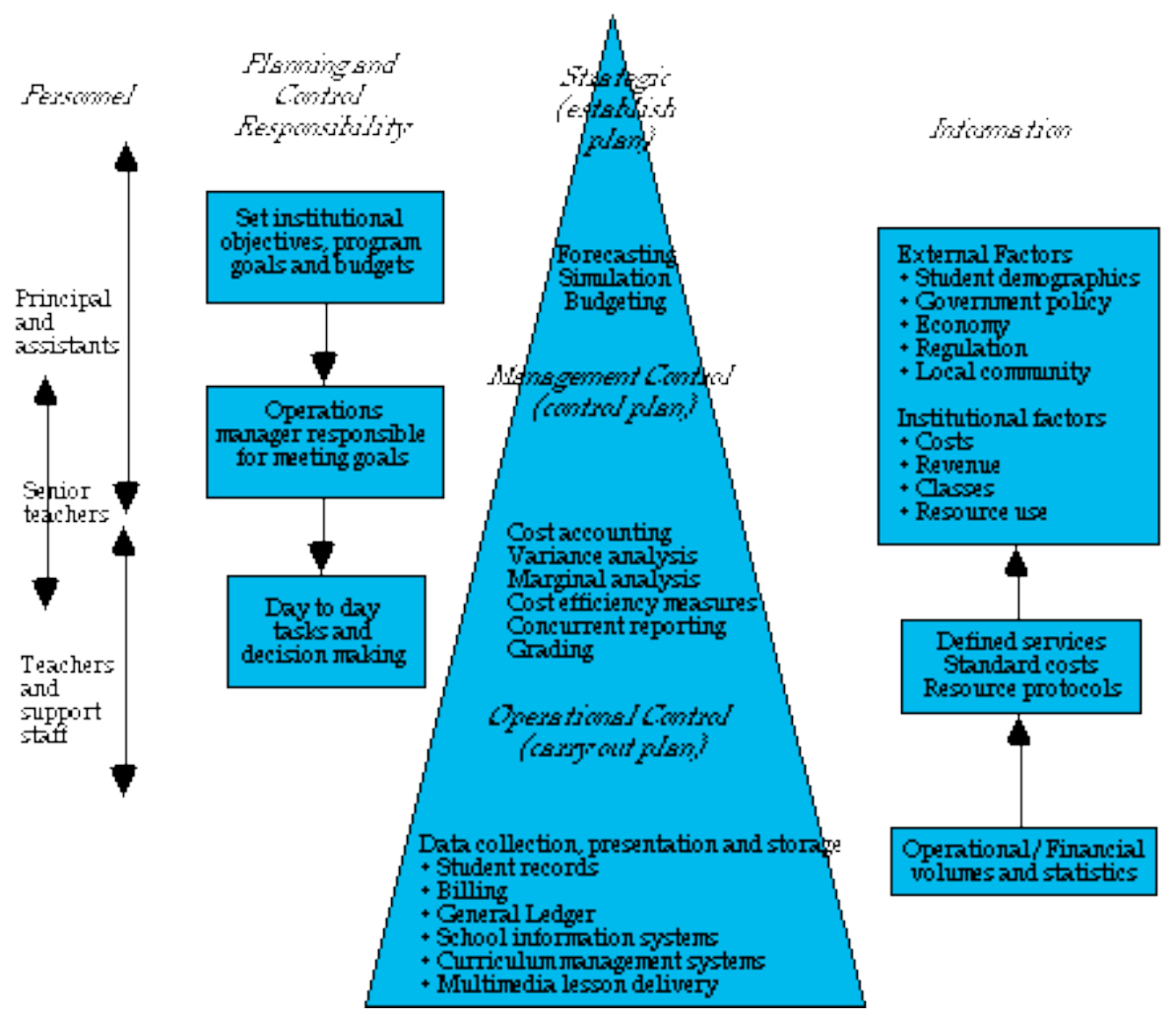

Figure 1: The information systems functions in the small educational organisation.

Introduction of a MIS system in this way does not allow devolution of responsible to the school level. The school management does not have a choice. They are not able to contract out training or support and are not able to choose some other system as proposed in the recommendations of Scott report This system does not have a mechanism for identifying the needs and objectives at the school level cannot easily be used for functions other than those for which packages have specifically been supplied.

The traditional information system department in a large organisation has the expertise and structure to develop sophisticated and effective planning. Figure 1 illustrates the major difference between a traditional information system organisation - the basic figure - and compares it to the information systems management structure of a small educational organisation - the additional descriptions. The major differences occur at the level of planning and control, in this type of organisation the 
responsibility overlaps and is often shared in the flat organisational structure.

As schools increasingly move toward the utilisation of computers to manage functions such as grade reporting, attendance and scheduling, it becomes important to examine how these school information systems contribute not only to more efficient administration, but to more effective decision-making, and to identify the organisational factors associated with effectiveness.

The need to examine the uses and potential uses of school information systems flows from the confluence of two currents in educational administration. At the same time as the technology to manage information in the schools has become increasingly available, the need for more information and for more widespread use of the information has been tied to the efforts at making schools more effective. In a chapter entitled "Can We Have Effective Schools?" and at other points in A Place Called School, Goodlad (1984) emphasised the need for data at the local school level to bring about improvements in the interactive system of principals, teachers, parents, students, and curriculum. Similarly, Sizer (1985) made site-based planning and shared decision-making hallmarks of the reforms he urged. In a study of processes in school improvement, Dennis (1986) identified data collection and the production of school profiles as a key step.

The role of the educational administrator is both to make decisions which move the school closer to its primary purpose of educating students and to facilitate similar decision-making by teachers and others on the school staff. For these decisions, information about the student - as individual, as member of targeted groups such as cohorts and special needs populations, and as participant in classes and particular programs - is the critical unit of analysis.

\section{Perspectives on School Information Systems}

Businesses and industries appear to be moving toward greater use of computerised information and process to aid in strategic and long-range planning. Decision Support systems and Expert Systems are able, in different ways, to answer "what if" questions (Yoo \& Digman, 1987; Turban \& Watkins, 1986; Applegate, Chen, Konsynski \& Nunamaker, 1987). A review of the literature showed that schools have barely begun to utilise information systems to answer "what is" questions. Three directions in current work were identified. First, reports of projects to develop and use school information systems for use in decision-making in schools or school districts described the process of design, the efforts at involving school staff in using the information, and the extent to which the projects succeeded. Second, "how to" and anecdotal articles described the use of 
software for increased efficiency. Finally, position papers raised issues about the conditions under which information is used, identified possible scenario for success in promoting use of school information systems and suggested agendas for research. It may be noted that the material reviewed was overwhelmingly descriptive, and the base of knowledge in the field seems to he at a stage where descriptive research is the most appropriate. The literature was therefore reviewed with the goal of identifying indicators of the use of information in educational decisionmaking and of identifying conditions that appeared to be associated with this use. These indicators and conditions formed a base upon which this study was carried out.

\section{Effectiveness in the Use of School Information Systems}

Two major projects, underway since the early 1980 's, have had as their thrust the development of comprehensive information systems by mean of which school districts would be able to utilise information for decisionmaking at various levels

In the Systematic Evaluation Project (Burstein, 1984a, 1984b, 1985; Sirotnik \& Burstein, 1984, 1987 Sirotnik \& Oakes, 1986), the project team worked collaboratively with selected administrators, teachers and counsellors, in a secondary school of 2,000 students in suburban Los Angeles, to determine the information needed and how it should be reported. They found that teachers most utilised the individual student level of information and that the formatting of the report to fit on one notebook sized sheet of paper was important to them. Teachers also wanted all information on a given class presented on one page and, although they had no trouble in reading more elaborate tables, they chose a simple bar format. Teachers appeared less receptive to the class level of information, because of their greater familiarity with individual student data and their concern with possible misuses of information, violations of confidentiality and the development of self- fulfilling prophecies. When the data were aggregated at the school level, the administrators became more interested, and the teachers less so.

After comparing the project's reports with those of systems in other schools or districts, Burstein (1985) concluded that the nature of the data presented in the reports reflected the decision-making style of the school or district (centralised versus decentralised), expectations about the knowledge base of the reader of the reports, and the environment within and outside the school. He pointed out the possibilities of using existing data in school districts for "long range planning, pulse monitoring, student decision-making, program decision-making, and informing educational policy" (Burstein, 1984b, p. 313).

In the Management of Instructional systems (IIS) Project, Williams and Bank (1984,1985: Bank \& Williams, 1987) examined the practices in two school districts to assess the impact of the IIS in use. They asked teachers 
and administrators to discuss a single important decision for which they had used district IIS information; to assess the importance of that information; and to describe the satisfaction they felt with the information, the processes they used it in and their own behaviour.

The authors concluded that the necessary characteristics for data utilisation in decision-making occur when "the data are viewed as valid; the school's culture has been prepared to accept the system; the information users continue in their decision-making roles; and, perhaps the most important, the decisions that the data are to influence are viewed as having important consequences" (Williams \& Bank, 1984, p. 21).

Bigelow (1986) examined the utilisation of the Delaware Educational Assessment Program Management Information System, before and after local access was provided to all school administrators and practitioners through a state- wide telecommunications networked to a Digital VAX $11 / 785$. Begun in 1978, the system provided standardised test scores for students in grades 1-8 and 11. Contrary to expectations, there was no greater demand by teachers or principals, nor was there any improvement in the application of the information to the identification of student needs or the development of instructional solutions. Bigelow found that the users of the system were primarily clerks and middle managers, and that teachers preferred requesting reports from the central computer staff rather than accessing the information themselves although the paperwork for requests was more time consuming than direct access.

Cannings and Polin (1987) surveyed the use of the computer as an administrative tool in thirty high schools in California. They found that computers were located chiefly in the main administrative office, but not the principal's office, that principals focused more on information retrieval than policy analysis, and that administrators could only envision automating current tasks rather than accomplishing new ones. They concluded that as control of administrative functions was moving from the district office to the local school, intensive training of administrators in the use of computers and in how to get the software to do what one wanted was essential. They also found that teachers needed direct access to the administrative microcomputers as well as training in their use.

Gibbens (1986), Hartmann (1984), Hull, Walker and Murphy (1986), and Schneider and Burgos (1987) in separate investigations also found local control of system content, report design and accessibility were key issues in the utilisation of information for decision-making.

Cooley and Bickel (1986), working in the arena they identified as "decision-oriented educational research," concluded that a computer-based information system was an essential component of decision-oriented educational research. With a computer-based system, feedback from 
multiple indicators could be examined, information could be displayed in ways that were meaningful to different audiences, and information would be available in a timely manner to address "hot" issues (1986). Cooley and Bickel (1986) cautioned that in developing a school information system "it is important not just to 'automate' the information requirements of the current system but to reconsider the broad aims of the educational system" (p.77). The work of Cooley and Bickel, therefore, was directly related to the aim of this study to examine differences between schools which used their information systems only for increased efficiency or "just to automate" and schools which used their systems for increased ability to make decisions.

\section{School Information Systems and Increased Efficiency}

Only one study was identified which attempted to assess the impact of a school information system on efficiency. In a commissioned study of Columbia Computing Services' "The School System," Arthur Anderson \& Co. (1985) found that scheduling conflicts were reduced, grades were reported with less labour and fewer errors, other analyses of grades could be produced without additional clerical time, teacher and clerical effort for attendance keeping were reduced, and school/parent communication was increased.

Examples of the many publications that emphasised the use of school information systems to reduce paperwork are those by Crawford (1985a, b, c) and Dempsey (1987). These articles presented general guidelines for software use and selection with no mention of integration of information, electronic control of the flow of information, or possible use of the same information for decision-making or planning.

\section{Indicators Identified}

Two types of indicators emerged from the review of the literature and were incorporated in the research design:

- Indicators of the use of the information system for effectiveness in decision making included: a) locus of power in decision making as it relates to use of the information system; b) utilisation of information at the organisational as well as the clinical level; c) addressing concerns of confidentiality versus accessibility; d) use of information as a catalyst for discussion in grade, department or school meetings; e) use of longitudinal information; $\mathrm{f}$ ) development of student profiles; and g) use of the system to evaluate programs.

- Indicators of conditions associated with such use included: a) availability and placement of microcomputers; $b$ ) freedom with which reports can be requested by various members of the school staff; c) desire of teachers for information; d) role of user groups within the school; e) role of teachers in the content, format and readability of in-house 
reports; and for training of personnel on the administrative,

pedagogical and clerical staffs.

In this study, school information systems were defined as integrated computer-based software that includes data on student grades, attendance, classes and demographics, and the ability to aggregate and summarise it in ways that can become meaningful to administrators and their staffs. The use of school information systems for efficiency was defined as use aimed at bringing about savings in fiscal resources and / or in the time of teachers, counsellors, schools administrators and other staff in the routine collection of data (such as daily attendance reports) in the routine manipulation of data (such as school scheduling) and in the generation of standard or mandated reports (such as report cards). Use of computer-based information systems for more effectiveness in decision making was defined as use aimed at increasing the information upon which educational decisions were based and/or aimed at increasing the number of teachers, counsellors, administrators and other professional staff who had access to and used the information. Three questions were addressed in the study:

1. What differences are there between the levels of efficiency and effectiveness in the use of school information systems?

2. Can institutional operating practices associated with greater effectiveness be identified?

3. To what extent is greater effectiveness associated with more participatory decision-making?

\section{Current MIS systems in small educational organisations}

A survey was administered to management level people working in a variety of such systems. The survey participants included primary and secondary administrators, consultants to schools, trainers and people working in tertiary institutions The survey was designed to obtain information about the current use of information technology at the personal level, at the workplace and in related administrative activity.

Efficient and effective use of communication is an essential feature of any successful organisation. Questions related to communication revealed that the majority of respondents used an external email system for communication, with very few using an in-house LAN system. Most users reported Keylink as the predominant system used for communication outside their organisation. The Keylink email system is designed for curriculum support with an extensive calendar of events designed to link together schools and children throughout NSW and VIC. Most users reported this teaching aspect as the major function of their use of the system with use for administration not mentioned by the respondents. For communication within organisations respondents reported a small 
number of dial in computer linkups and email on a LAN, but the majority reported use of the technology to produce bulletins and newsletters as its main function in communication.

For the administrative process the vast majority of respondents reported the OASIS management information system as the key administrative support system. These systems varied in size depending on the size of the small organisation with the Administration and Staff and Student records packages reported as the most commonly used. A number of respondents reported imminent introduction of the finance package. Some of the respondents also reported that Macintosh machines were being used. The only other administrative packages reported were Attache and the MacSchool series. Of course the OASIS package has been introduced in governments schools throughout the state of NSW, for no cost to the school other than some component of the staff training costs. It is understandable that it is being used so extensively.

When asked about the type of equipment used and the percentage of time the equipment was used for various functions within the small organisations, there was a wide variety of answers given. The percentage use for teaching varied from over $90 \%$, to less than $15 \%$, for administration the variation was similar and for administration of student information the use was consistently reported as low, with average figures of teaching $(55 \%)$, general administration (31\%) and student administration $(14 \%)$. The figures indicate that equipment is being used almost as much for administration as for teaching with some of the respondents reporting duplication of student data at the department level as one of the reasons for the high administrative use.

The respondents reported a variety of computers in use for various functions within the small organisations. The majority of machines reported used within the classroom were Apple brand Apple IIEs, Macintosh Classics and Macintosh LCs. A small number of respondents reported having access to a machine on their desk with this more prevalent in training organisations and tertiary institutions than in schools. Interestingly the administrative hardware reported to be most prevalent was the OASIS system which is DOS based and has been supplied by a number of manufacturers. The respondents reported Macintoshes as the predominant home use machine with a small number of PCs. Only three respondents reported principals having a computer on their desk with two of the three having an OASIS system. This finding supports Caputo's (1988) third problem with the introduction of management information systems to small organisations ie. the IT technologies typically found in the small educational organisation is mostly discrete units of equipment, usually based on a classroom, office or library, with no plan for integration or networking beyond the geography of the room and no integrated information systems solution for the whole organisation. 
A question asked about the need for links between platforms. The responses indicated a strong desire to transfer information between the two major platforms. With the use of the OASIS system in schools for administration and the Macintosh machine appearing as the most prevalent machine for the rest of schools organisation, there was concern expressed about the lack of ability for the two systems to communicate. This has tending to result in lack of use of the detailed information available from the administrative data systems and considerable inefficiency in use of this data through duplication.

In several anecdotes, it was pointed out to us that an integrated strategy was not available for school management information systems. Some training was provided to support staff prior to the implementation of the technology, but more often the associated equipment arrived with poorly explained manuals and even less friendly computer interface. This lack of understanding of change, anxiety and frustration was also augmented by the fact that the system contained elements which were specific to the school context. For example, the technology was in part 'locked-up' and made less friendly in that, even if the staff were familiar with a standard word processing application, this was not allowed on the implemented system. The system allowed only the specially written word processing program to be used. This has meant that the staff cannot undertake staff development programs outside the education system for instant skill development, as the software is not a standard package, and secondly, that once the skills in using the software are developed, the approach effectively alienates their skills from the mainstream of most microcomputer applications users.

In an earlier study Hedberg (1982) in which a series of educational managers and word processing users were asked about their understanding of the technology they were using and how they saw the development of systems, and equipment over the next year, it was clear that the operators while familiar with the one system saw more clearly the impact of the system than the managers who were planning the development of the systems over the next budget period. Indeed, the planning involved an expense of around $\$ 14,000$ to add an extra word processing terminal to a centralised system, at a time when the cost of a microcomputer system was around $\$ 2,500$. The resulting impact was diminished by the fact that there was the belief that the centralised system was preferred in that it would enable the same system to be employed and documents could be copied to other areas of the organisation. No analysis was undertaken of the number of documents required to be transferred, nor was there any understanding of the options available on the existing system, which enabled files to be converted to standard operating system format and automatic conversion to run on the cheaper systems. 
Small educational organisations must manage more varied forms of information as they are the essential elements of the organisation. Unlike any other human services organisation, educational structures are more than the manipulation of computers or simple data structures. A guideline for future palming will be the school's ability to marshal all its data management resources to address all its functions. The more part solutions are proposed the more the school will not achieve data systems maturity.

\section{School Information Systems in two states}

To control the variables associated with the use of different systems, an early decision in the research design was to limit the investigation to one school information system. A necessary first step, therefore was the identification of a microcomputer-based school information system with integrated functions and a substantial body of users, which had been well reviewed and which was willing to participate in the project.

Based upon a review of available systems (Wright and Valbonesi, 1985), 'The School System" (Columbia Computing Services, 1987) was selected. "The School System' has integrated modules for student records, academic progress, student scheduling, discipline tracking, attendance and report generation. At the time of selection, it was in use in more than 2300 sites worldwide and more than 1670 sites in the United States. Wright and Valbonesi (1985) conducted their evaluation of systems in junior and senior high schools using real and current data. They evaluated systems for product scope and function, ease of use, technical considerations, support and services after sales, credibility and history of the product, and reputation of the vendor. "The School System" had the highest rating. Among its strengths were user defined fields, consistent data entry mechanisms, ease of learning, a multi-user capability and an open system design facilitating future development.

Columbia Computing Services, Inc. was approached and agreed to cooperate by sending their mailing labels to a third party mailer. This both protected the interests of the company in their site lists and protected the study from any interference in instrument design or site selection. It should be noted that no financial or other support was supplied by Columbia Computing Services, Inc.

\section{Instrument Development}

Six schools experienced in the use of "The School System" were identified in two states in the investigator's local area. Visits to these schools drew upon the techniques of the qualitative research tradition (Jacob, 1987) to amplify the understandings related to uses of the school information system, factors associated with use, and the vocabulary used in the schools to describe system use. A draft survey questionnaire was developed. 
A second in-person interview with the administrator most involved in the system at each school was then conducted. At the second interview, each administrator was asked to respond to the survey. The investigator reviewed the responses and discussed any which deviated from expectations based upon observations made in the first visit. In addition, the administrators were encouraged to identify any ambiguous items or concerns with the instrument as a whole.

The resulting instrument had three sections as follows:

Section A contained 7 multiple choice items related to school description (eg., grades served by the school, current enrolment).

Section $B$ contained 13 items, primarily multiple response, related to basics of use of the school information system (eg., the location of the microcomputers, the identification, by title, of those who had received training).

Section C contained 39 items. Integrated into the 39 items were four measures. Efficiency was represented by 12 items (eg., Report cards are produced more accurately since we have the system; Teachers have accurate class lists earlier in the school term or year). Effectiveness was represented by 11 items (eg., Reports produced by the system have been used by the school administrators to help them evaluate or make decisions about programs within the school; Teachers use information from the system to help them make decisions about the educational needs or programs of groups of students). Operational factors were represented by 10 items (eg., A user group of interested faculty meets to improve the system; Reports are specifically designed within the school for use by the school). In addition, to assess the level of Participatory decision making apart from the school information system, 6 items were adapted (with permission) from Organisational Variable 5, "Character of decision-making process" of the Profile of Organisational Characteristics (Likert, 1967 pp. 205-207) (eg., The decision-making processes in the school contribute substantially to the motivation to implement these decisions). Items from the four measures were interspersed and called for Likert-type responses on a scale ranging from 4 for Always to 1 for Never. The instrument was thus based on the indicators revealed through the review of the literature and on interviews with experienced users of the school information system. This $\mathrm{w}$ as followed by the pilot administration of the instrument to the interview subjects and a second interview which led to minor revisions in language. The investigator therefore believes the instrument had a reasonable level of content validity.

\section{Population}

Survey questionnaires were mailed to site coordinators of 1,457 schools utilising the mailing labels for all schools in the United States using The School System. The site coordinator was the individual identified by each school as having responsibility for the operation of The School System. A follow-up postcard urging response was sent to all sites four weeks later. 
A total of 757 responses were received and one non-deliverable, bringing the percentage of respondents to $52.0 \%$. Of 757,160 did not answer the items in Section C primarily because they believed they had insufficient experience with the system. Therefore 597 survey responses were entered for analysis. Because of the mailing arrangements agreed to with Columbia Computing Systems, no direct follow-up of non-respondents could be carried out nor could any observations be made regarding the non-responding portion of the population. The results, while not representative of all schools using the School Information System, do provide good information on the practices of a large number of varied schools. Of the 597 schools responding, 432 identified themselves as serving high school grades. They formed the population for this study.

\section{Analysis and Findings}

The data resulting from this study were analysed in relation to each of the three study questions posed earlier.

\section{What are the differences between the levels of efficiency and effectiveness in the use of school information systems?}

To examine the differences between the levels of efficiency and effectiveness in the use of school information systems, a test of the difference in the means of the efficiency and effectiveness measures was carried out. In both the efficiency and effectiveness measures, the range of answers was from 1 for never to 4 for always. Therefore, the higher the mean, the more often the respondent was reporting a particular result or behaviour occurred. As would be expected from the review of the literature, the mean for efficiency, 2.9347, $(\mathrm{SD}=.500)$ was significantly higher than the mean for effectiveness, 2.4804, $(\mathrm{SD}=.507),(\mathrm{t}=23.62, \mathrm{~N}=$ 407, $\mathrm{p}<.001$ ).

Table 1 shows the means and standard deviations for the 5 highest scoring items on each of the two measures. It should be noted that on the measure of effectiveness, all of the remaining six items received mean scores lower than 2.5. On the measure of efficiency, however, two of the remaining seven items scored above 3.0 and one more scored above 2.5.

Table 1: Five Highest Scoring Items: Measures of Efficiency and Effectiveness

\begin{tabular}{lcc}
\hline Measures of Efficiency & Mean $^{*}$ & SD \\
Item & 3.66 & .63 \\
$\begin{array}{l}\text { 1. Teachers have accurate class lists earlier in the term. } \\
\text { 2. Reports produced by the system are for people within the school }\end{array}$ & 3.53 & .57 \\
$\begin{array}{l}\text { such as administrators, teachers, or counsellors. } \\
\text { 3. Student scheduling takes less time than before we had the }\end{array}$ & 3.46 & .77 \\
$\begin{array}{l}\text { system. } \\
\text { 4. Report cards are produced more easily since we have the system. }\end{array}$ & 3.46 & .93 \\
5eport cards are produced more accurately since we have the & 3.42 & .98 \\
\hline
\end{tabular}


Measures of Effectiveness

Item

1. The reports produced have more information than before we had the system.

2. Reports produced by the system have been used by the school administrators to help them make decisions about programs within the school.

3. The school administrators use information from the system to help them make decisions about the educational needs or progress of groups of students.

4. Teachers and administrators informally discuss information

$3.45 \quad .72$

$2.94 \quad .79$

with each other that they have gotten from the system.

5. Counsellors use information from the system to help them make decisions about the educational needs or progress of groups of students.

* Scale of $4=$ "always" to $1=$ "never"

\section{Can institutional operating practice associated with greater effectiveness be identified?}

To identify institutional operating practices associated with greater decision-making effectiveness, a stepwise multiple regression was carried out in which the operating factors measure and selected items from the school description and basic use portions of the questionnaire were regressed against the effectiveness measure. A second stepwise multiple regression analysis examined the variance associated with each item of the operating factors measure. In the third analysis a median split of the population using the effectiveness measure score was carried out. Each of the categorical variables of school description and basics of use of the school information system were examined for relationships utilising Chisquare analysis.

In the first stepwise multiple regression analysis, the independent variables of size of school (measured by enrolment), number of years using the school information system, number of microcomputers in use in the school, and the score on the operational factors measure were entered. Only the score on the operational factors measure and the number of microcomputers in use in the school stayed in the equation. The score on the operational factors measure contributed $34.5 \%$ of the variance $(p<.001)$ and the number of microcomputers in use added $1.5 \%(\mathrm{p}<.01)$ for a total $\mathrm{R}$ Square of .3601.

In the second stepwise multiple regression analysis, the items of the operational factors measure were regressed individually on the effectiveness measure score. Four of the ten items remained in the equation, with an alpha or .001. They were: Teachers participate in the design of data entry forms ( $R$ Square Change $=.1955$ ); In-house reports from the system, other than daily attendance, routinely go to school administrators $(\mathrm{R}$ Square (change $=.0843)$; Teachers participate in the 
design of reports (R Square Change $=.05)$; and In-house reports from the system, other than daily attendance, routinely go to teachers ( $R$ Square Change $=.029$ ).

In the Chi-Square analysis, there were 6 multiple response items of the school description section (location of school, enrolment, number of administrators, number of faculty members, number of people employed for clerical or secretarial functions, and percent of the students eligible for free or reduced price lunch) and 11 items from the basic use section. Three of the items were "yes/no" - asking whether the school had prior experience with a microcomputer system, whether it used other software in conjunction with "The School System" and whether it networked its microcomputers. The remaining items were multiple response and were coded as individual dichotomous variables. They included: a) the specific modules of the school information system in use; b) the locations of the microcomputers; c) the titles of those who had received training from the vendor; d) who had received training from someone in the school or district; e) who had the ability (knowledge and password to write to the computer; f) who had the ability to read from the computer; g) who could request standard reports from the site coordinator; and h) who could request information not in standard report form.

It may be noted that none of descriptors of the school, including the number of clerical personnel, reached an alpha of .05. Table 2 shows the items which reached at least that level of significance.

Table 2: Basic use with high effectiveness / low effectiveness schools with a median split

\begin{tabular}{lccccc} 
Item & $\begin{array}{c}\text { N Pos } \\
\text { HiEff }\end{array}$ & $\begin{array}{l}\text { N Pos } \\
\text { LoEff }\end{array}$ & $\begin{array}{l}\text { N Neg } \\
\text { HiEff }\end{array}$ & $\begin{array}{l}\text { N Neg } \\
\text { LoEff }\end{array}$ & $\begin{array}{l}\text { Chi- } \\
\text { Square }\end{array}$ \\
\hline Which modules of the School System are & used in & your school? \\
Student Records & 195 & 175 & 13 & 33 & $8.82^{* *}$ \\
Student Scheduling & 206 & 190 & 2 & 18 & $11.82^{* * *}$ \\
Academic Progress & 191 & 160 & 17 & 48 & $16.41^{* * *}$ \\
Attendance & 176 & 135 & 32 & 73 & $20.38^{* * *}$ \\
Discipline Tracking & 81 & 47 & 127 & 161 & $12.29^{* * *}$ \\
Report Builder & 52 & 27 & 156 & 181 & $9.00^{* *}$ \\
Use Networking & 81 & 54 & 125 & 152 & $7.45^{* *}$ \\
\hline Including the "host" microcomputer where are the micros or terminals located? \\
Principal's office & 53 & 43 & 111 & 165 & $5.90^{*}$ \\
A.P.'s office & 71 & 68 & 93 & 140 & $3.96^{*}$ \\
\hline Who received training in using The School System from the vendor or user group? \\
Site coordinator \\
\hline 7
\end{tabular}


Who received training in using The School System from someone in the school or school district?

$\begin{array}{llllll}\text { One or more admins. } & 57 & 54 & 117 & 177 & 3.93^{*}\end{array}$

Who has the ability (knowledge and password) to write to the computer records?

$\begin{array}{llllll}\text { Site coordinator } & 132 & 144 & 43 & 92 & 8.82^{\text {** }}\end{array}$

$\begin{array}{llllll}\text { One or more admins. } & 98 & 106 & 77 & 130 & 4.51 \text { * }\end{array}$

Who has the ability (knowledge and password) to read from the computer records?

\begin{tabular}{llllll} 
Site coordinator & 126 & 138 & 51 & 100 & $7.09^{* *}$ \\
\hline
\end{tabular}
${ }^{*} \mathrm{p}<.05,{ }^{* *} \mathrm{p}<.01,{ }^{* * *} \mathrm{p}<.001$

\section{To what extent is greater effectiveness associated with more participatory decision-making?}

To examine the extent to which greater effectiveness was associated with more participatory decision-making, a stepwise multiple regression was carried out in which the efficiency, effectiveness, and operating factors measures were regressed on the decision-making measure. Second a test of decision-making scores for high and low effectiveness schools using a median split was carried out. Finally, a correlation matrix of effectiveness, efficiency, operating factors and decision-making measures was developed.

In the stepwise regression analysis of efficiency, effectiveness, and operating measure scores on the decision-making measure score, effectiveness contributed $11.64 \%$ of the proportion of the variance $(p<.001)$ and operational factors added $1.13 \%(\mathrm{p}<.001)$. Efficiency did not enter the equation.

$\mathrm{T}$ tests of the difference in the means on the decision-making measure between those with high efficiency and those with low efficiency, using a median split at 2.523, reinforced the relationship. Those with high efficiency scored a decision-making mean of $3.0476(\mathrm{SD}=0.311)$ and those with low efficiency scored a decision-making mean of $2.8840(\mathrm{SD}=0.383)$ $(\mathrm{t}=-4.74, \mathrm{~N}=409, \mathrm{p}<.001)$.

Table 3: Correlations among factors

\begin{tabular}{llll} 
& Effectiveness & Operating Factors & Decision Making \\
\hline Efficiency & $.7032 \mathrm{~N}=407$ & $.4945 \mathrm{~N}=410$ & $.2124 \mathrm{~N}=403$ \\
Effectiveness & & $.5705 \mathrm{~N}=414$ & $.3256 \mathrm{~N}=409$ \\
Operating Factors & & & $.2442 \mathrm{~N}=418$ \\
\hline
\end{tabular}

Note: For all correlations, $\mathrm{p}<.001$

Finally, examination of Table 3, Correlations among Effectiveness, Efficiency, Operating Factors, and Decision-Making, shows the interrelationships among these reported observations and behaviours. As 
might be expected the strongest relationship is between effectiveness and efficiency. The relationship between operating factors and effectiveness is stronger than that between operating factors and efficiency, and the relationship between decision-making and effectiveness is also stronger than that between decision making and efficiency.

\section{Discussion}

This study showed that school administrators tend to use school information systems more for greater efficiency in traditional functions, such as production of report cards and school scheduling, than for more effectiveness defined as the utilisation of more information about students or the utilisation of student information by more people in the decisionmaking processes. It also revealed a number of operating procedures linked to utilisation of the systems for greater effectiveness and indicated a positive relationship between use of the systems for effectiveness and more participatory decision-making.

The operating factors which contributed most to use of the school information systems for greater effectiveness were the following:

1. Teacher involvement in the design of data entry forms and reports;

2. Regular distribution of reports generated by the system to both administrators and teachers;

3. Utilisation of all possible modules of a system including the ability for a school tailor its own reports

4. Having more microcomputers, networking the microcomputers, and having microcomputers in the principals' and assistant principals' offices;

5. Training by the vendor for at least the site coordinator and training by the school or school district for administrators and others.

While, this study was limited to high schools using a particular school information system, the results echoed findings in studies of successful use of systems in other industries (Magal \& Carr, 1988; Raghunathan \& Raghunathan, 1989; Robertson, 1989). The findings are particularly related to Zuboff's (1988) major study of the impact of technologies in organisations across five industries (paper and pulp production, telecommunications, insurance, banking and pharmaceutical). In Zuboff's work, concepts quite similar to efficiency and effectiveness, as used in this study, were called automating and informating.

Zuboff (1988) defined automating as the utilisation of technology to replace the human body with a machine that can perform more quickly and more continuously. however, she pointed out "the same technology simultaneously generates information about the underlying productive and administrative processes through which an organisation accomplishes 
its work. It provides a deeper level of transparency to activities that had been either partially or completely opaque.... (It) creates a vast information presence that now includes data formerly stored in people's heads, in faceto-face conversations, in metal file drawers, and on widely dispersed pieces of paper" (pp. 9-10). Informating is the conscious use of this information to transform the operations of an organisation as well as how decisions about the operations are made.

Automating, in Zuboff's view, is a necessary precursor to informating. However, informating does not necessarily follow automating. Without planned use of the outcomes of automating, she found, the potential for informing remained largely untapped. She stressed the need for training, for "egalitarian access to the emerging electronic text" (p. 356) and for new lines of communication. Her observation of the changes in hierarchical relationships within "informating" organisations and the barriers to such changes in organisations which resisted "informating" may explain the difference in this study between the efficiency and effectiveness scores as well as the relationship between effectiveness and participatory decisionmaking.

Zuboff explained a reluctance to informate in terms of fears of a loss of power and of changes in the organisational structure. Another explanation may be found in how administrator's view information from a computer in relation to that which they experience directly. Perhaps an analogy can be drawn between the use of computer information by educational administrators and Sergiovanni's recent comments on their use of theory. Sergiovanni (1989) categorised educational administrators as "mystics" who saw no relationship between theory and practice, "neats" who saw theory and research as driving practice, and "scruffies" who saw theory and research as only one source of knowledge used to help them reflect upon practice. This taxonomy may further explain the reluctance of some administrators to utilise the systems. Mystics would be seen as those who have no need for any information except that which they experience directly. They would, therefore, put the school information system in the attendance office because that is the most constant record keeping function. Neats, on the other hand, would believe completely in any information that came from the computer. They are probably as rare as those educational administrators who practice solely by theory. Scruffies would be the administrators who were able to find ways to integrate information from the systems into the knowledge gained from practice and theory. Indeed, Polanyi (1962) defined the act of gaining knowledge as a personal one in which each individual incorporates information into her or his own framework and changes the framework itself as needed to incorporate the new information. The need to foster and develop information "scruffies" is one of implications of this research discussed in the next section. 


\section{Implications}

Implications for the field of educational administration have emerged rather clearly from this study. In the following paragraphs, they are sketched briefly in terms of practice, research and professional education with the hope that this will lead to further discussion, elaboration and investigation.

Carrying out these practices is more likely to result in the utilisation of both the informating and automating powers of school information systems. While one can see the link between more participatory decisionmaking and effective use of systems, it is not clear which must come first. However, it is fairly clear that shared decision-making will not take place without shared access to the information on which decisions are to be based.

Implications for further research in the field include: a) replication of the study in schools using other school information systems; b) examination of critical time periods in the use of school information systems, particularly changes in effects and related factors as schools become more accustomed to them; c) investigation into relationships between the use of information systems and student outcomes; and d) deeper research into the personal qualities (including age sex, and education) of administrators who use the systems for effectiveness.

Implications for programs in educational administration include course work on practices that will ensure the utilisation of information and help clarify the relationship between information and decision-making. Therefore, courses in administrative computing need to include not only material about system selection and utilisation practices, but help for the future administration in moving data to information and thence to knowledge. This includes developing conscious synthesising of material drawn from theory, experience, and information systems. Future administrators need to learn how to "interact with the evidence, interpret its meaning, decide its relevance and hence determine whether and how they will permit the evidence to influence them" (Kennedy, 1984, P. 208).

Mulkeen and Tetenbaum (1989) have called for new programs to prepare educational administrators for the "knowledge/information age." The programs they envisioned stress "activity versus passivity, change versus entrenchment, dynamic decision-making versus static information, process versus product, people versus structures..." (p. 14). It is exactly this emphasis on process that is heeded in the portion of an administrator's education that is devoted to the use of information systems. If, instead, the emphasis in programs for educational administration remains at the "how to" level of training in the use of various software packages for increased efficiency (Garland, 1990), the programs will continue to foster the 
development of information "mystics" and "neats. " That is, there will be those administrators who continue to relegate automated systems to specific functions, carried out by others, for the sake of saving time. And there will be those few administrators who rely solely on information they themselves have produced from their manipulations of data.

\section{An integrated information system}

If schools are going to be able to integrate data into a total information systems strategy for all data in the organisation and come up with an integrated information system for the whole organisation, the planning for this process needs to be based on a complete structure, and the educational administrators will need to have the expertise to implement such systems. Such a structure could perform the necessary integration planned around a basic network such as that shown in Figure 2. Each of the network elements itself consists of many links as illustrated in figures 3 to 6 . The figures illustrate some of the links and are certainly not complete, however, they do point to the complexity of the educational organisation. The educational integrated information format is possibly more varied than any other organisation, in that it contains elements of publishing, library, financial management, people management and time tabling .

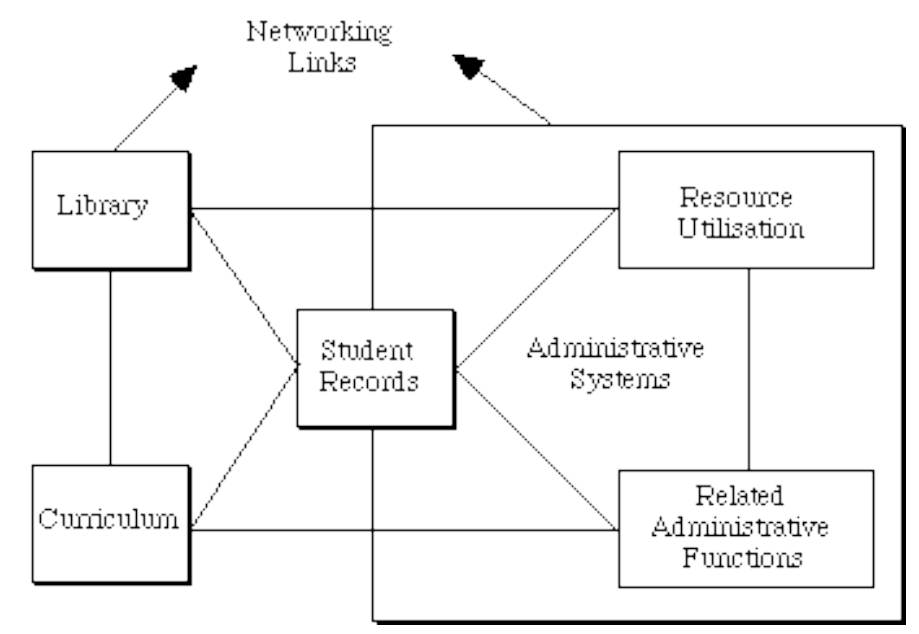

Figure 2: Basic Elements of an Educational Integrated Information System

If each element is further expanded links such as the following relationships can be established. In the student records section links would desirably include: 


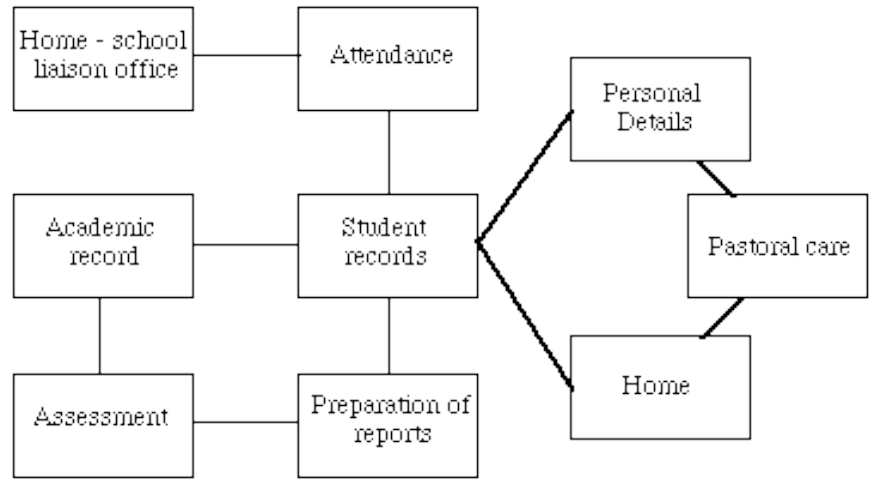

Figure 3: Student Records Subsystem

\section{Information systems and change}

The configuration of the information system and the methods of data capture are important for the users. If on-line testing, and learning modules are linked to the student record keeping systems then greater amounts of individual information could be kept leading to increased problems of data management and the need for specialised personnel to maintain the system (ensuring regular backup and archiving, etc.). The advantages of the technology might be rapidly outweighed by the increased specialised requirements if the manager does not fully appreciate the types of skills required. The most interesting issue in this regard is the lack of a clear cost-benefit analysis of the alternatives, from a series of perspectives: Hardware choice, Software choice, Telecommunications and networking possibilities, Organisational structure and restructure, and the mix of existing and specialised personnel.

\section{Information systems and work flow}

\section{Provision of extra features}

Planning for systems must take into account the needs of the new and added features which have increased over the life cycle of the hardware products. Many products are offered with new versions once or twice a year. The instant access to new features without the need for any or very little training is critical to the small educational organisation.

\section{Information flow}

The use of data can be seen from two directions. With the growth of an integrated information system, it can be expected that data needs to flow from library to student, from student to administration, from 
administration to teacher and from teacher to administration. If the teacher is called upon to use resources for presentation to groups there will also be the need for flow of information from library to teacher who may be located in their own classroom or some specialised large group presentation space. The authors contend that the possibilities of information flow, provided it is handled at a sophisticated data interface level, can ensure that the hoped for developments in resources-based learning might finally occur. The problems with using presentation technologies in the classroom in the past have revolved around lack of access, and difficulty in obtaining the appropriate hardware on which to present. With integrated platforms, a feature which is likely to be even more so over the next few years, it is possible to move information from one site to another and to overcome the lack of teaching support staff.

It is likely, that there will be resistance to any system, if routine performance outputs of the system are not used sensitively. It is possible to quickly convert results per class into results by teacher, thus giving increased pressure to inflate grades and pass students. Within a context of mandated attendance and increasing retention rates for senior school students, this pressure could lead to inefficient practices of increased data entry staff requirements when automated and originator input would be preferred.

Administratively people are still working at the routine level of use, where they employ discrete elements in separate tasks. For example using a word processor to prepare a number of letters. There are few sites where the applications have moved into integrative uses, where data elements are combined into innovative forms of time saving, automatically producing each child's personal report, or individually developing a child's timetable to enable him or her to focus on the development of remedial or enrichment curriculum activities. No sites were using information systems in a generative way where the information was used to provide more effective decision making about the student's learning performance or providing information in a format which is more comprehensible to the learning style of the student.

\section{Planning educational integrated information systems}

Interface issues are currently the major challenge facing software selection in the curriculum area. Most educational software is using technologies which must be able to support more than a command line interface. The recent growth in windows environments and the need to share information which is substantial in size such as movie files poses challenges to the type of minimal information systems solutions offered by a largely text and numbers style of DBMS. The possibilities that need to be considered must address the need to incorporate pictorial information into the database structure. This information can be linked through library 
networks to classrooms and individual study systems (such as portable and personal notebook computers) and also to the testing and record systems of the administration.

Many educational packages are trying to provide a microworld in which the student can be immersed. It is a small step to an educational experience in which the student can make decisions, explore and investigate different environments in ways that which can make the existing print and teacher led presentation seemvery sterile. While exploring these virtual realities, the data on each individual child will provide a greater insight to their learning process than the simple grade at the end of each term or year.

In the business and industrial contexts we can see the growth of embedded performance systems as a factor in making the use of information systems more accessible to the user and to the generation of the outputs required by the user. In educational information systems, we should expect similar developments. There is an increasing use of the personal notebook as an individual learning tool which can be used to manipulate the form of representation of information to a form useful for the individual user. Thus data can be presented graphically to identify underlying trends and to provide instant recognition of the underlying principle. The result of such systems will be the more rapid concept attainment for those who can use and access such systems.

The major trend in larger organisations is the growth in networks thereby enabling the interrelation of ideas and individual information systems These would be extremely powerful for the educational organisation if it was provided. Designing information systems which lock off part of the technology or impose arbitrary constraints on use will be positively circumvented by the inventiveness of the environment. In small educational organisations, the approach to change in this decade needs to be addressed in new ways and holistically.

Taking on one innovation at a time is fire fighting and faddism. Institutional development of schools and districts increases coherence and capacity for sorting out and integrating the myriad of choices, acting on them, assessing progress, and (re)directing energies. The greatest problem faced by school systems is not resistance to innovation but taking on too many changes indiscriminately. Selectivity and synergy replace ad hocism in institutionally developed organisations. (Fullan, 1991, p349)

In summary, planning for the small educational organisation provides one on the most ulteresting challenges for information systems strategies over the next five years. The organisation, is extremely flat compared to other types of organisations. The range of outcomes and inputs into the system can be considered to be vast compared to the focussed information systems of the industrial orgalusation. The lack of professional expertise 
and organisational structures can allow for greater individual adaptation than in larger and more rigid organisations. We may truly see, concerns for information being replaced by systems which can legitimately be considered as providing knowledge. It might even be possible that the implementation might take the ideas further to achieve expertise and eventually wisdom. Schools and districts implementing school information systems will find them most useful if they have a commitment of interest from the top administrators, invest in training at all levels, involve teachers in system operation, and share the information with both teachers and administrators.

\section{References}

Applegate, L., Chen, T., Konsynski, B. \& Nunamaker, J. Jr. (1987). Knowledge management in organizational planning. Journal of Management Information Systems, 3(4), 20-38.

Arthur Anderson \& Co. (1985). "The School System" benefits survey. A report to Columbia Computing Services. Author.

Bank, A. \& Williams, R. C. (1987). The coming of instructional information systems. In A. Bank \& R. C. Williams (Eds.), Information systems and school improvement: Inventing the future. New York: Teachers College Press. (pp.3-10).

Bigelow, R. A. (1986, April). Information power: Use it or lose it. Reflections on the development and use of a state wide assessment information system. Paper presented at the annual meeting of the American Educational Research Association. San Francisco. (ERIC Document Reproduction Service No. ED 270 496)

Burstein, L. (1984a). Information use in local school improvement: A multilevel perspective. In Comprehensive information systems for local school improvement: A reality test in secondary schools. Papers from the Systematic Evaluation Project, fiscal year 1984. University of California Los Angeles Center for the Study of Evaluation. (ERIC Document Reproduction Service No. ED 263 111).

Burstein, L. (1984b). The use of existing data bases in program evaluation and school improvement. Educational Evaluation and Policy Analysis, 6, (3), 307-318.

Burstein, L. (1985). Specificity of information in data-based decision-making schools. Systematic Evaluation Project, final report. University of California Los Angeles Center for the Study of Evaluation. (ERIC Document Reproduction Service No. ED 266 158).

Cannings, R. R. \& Polin, L. (1987) The computer as an administrative tool: A survey of 30 high schools. In A. Bank \& R. C. Williams (Eds.), Information systems and school improvement: Inventing the future (pp. 39-55). New York: Teachers College Press.

Caputo, R. (1988). Management and Information Systems in the Human Services. New York: Haworth Press.

Columbia Computing Services. (1987). The school system (Computer program). Kent, WA: Author.

Cooley, W. \& Bickel, W. (1986). Decision-oriented educational research. Boston: Kluwer-Nijhoff.

Crawford, C. W. (1985a). Administrative uses of microcomputers, part I. NASSP Bulletin, 69, (479), 70-72.

Crawford, C. W. (1985b). Administrative uses of microcomputers, part II. NASSP Bulletin, 69, (480) 53-60. 
Crawford, C. W. (1985c). Administrative uses of microcomputers, part III. NASSP Bulletin, 69 (481), 95-98.

Dempsey, D. (1987, April). How to administer a school using technology. Tips for Principals from NASSP.

Dennis, D. (1986). Applications of computer technology in profiling and databased decision making Program report. Washington, DC: Office of Educational Research and Improvement. (ERIC Document Reproduction Service No. ED 277 159)

Fullan, M. G., \& Stiegelbauer, S. (1991). The New Meaning of Educational Change. 2nd. ed. New York: Teachers College, Columbia University.

Garland, V. E. (1990). Software trends in the training of school administrators. Technological Horizons in Education, 18(4), 86-88.

Gibbens, T. P. (1986). The administrative impact of computers on the British Columbia public school system. (ERIC Doc. Reproduct. Service No. ED 359451)

Goodlad, J. L. (1984). A place called school: Prospects for the future. New York: McGraw-Hill.

Hartmann, N. J. (1984, October). Successful introduction of student information management systems. Workshop presented at the Annual Conference of the International Society for Educational Planning, New Orleans. (ERIC Document Reproduction Service No. ED 257 186)

Hedberg, J. G. (1982). Technological awareness and levels of use of an innovation. In Educational research in the 1980s. Vol 2. Brisbane: Australian Association for Research in Education, pp 567-572.

Hull, T. R., Walker, A. \& Murphy, J. (1986). Transcript analysis: Using the data to improve schools. NASSP Bulletin, 70, (494), 97-102.

Jacob, E. (1987). Qualitative research traditions. A review. Review of Educational Research, 57(1), 150

Kennedy, M. M. (1984). How evidence alters understanding and decisions. Educational Evaluation and Policy Analysis, 6(3), 207- 226.

Likert, R. (1967). The human organization: Its management and value. NY: McGrawHill.

Magal, S. R. \& Carr, H. H. (1988). An investigation of the effects of age, size and hardware option on the critical success factors applicable to information centers. Journal of Management Information Systems, 4(4), 60-76.

March, J. (1987). American Public School Administration: A short analysis. School Review, 86, 217-249.

Mulkeen, T. A. \& Tetenbaum, T. J. (1989). Teaching and learning in knowledge organisations: Implications for the preparation of school administrators. Journal of Educational Administration, 28(3), 14-22.

Nolan, R. L. (1979). Managing the crisis in data processing. Harvard Business Review, March-April, 115-126.

Polanyi, M. (1962). Personal knowledge, Towards a post-critical philosophy. Chicago: The University of Chicago Press.

Raghunathan, B. \& Raghunathan, T. S. (1989). Relationship of the rank of information systems executive to the organization role and planning dimensions of information systems. Journal of Management Information Systems, 6(1), 112-126.

Robertson, D. C. (1989). Social determinants of information systems use. Journal of Management Information Systems, 5(4), 55-71.

Sarason, S. B. (1990). The Predictable Failure of Educational Reform: Can we change course before it's too late. San Francisco: Jossey-Bass.

Schneider, G. T. \& Burgos, F. (1987). The microcomputer: A decision-making tool for improving school discipline. NASSP Bulletin, 71(496), 104-112. 
Scott, B. W. (1990). School-Centred Education: Building a more responsive state school system. Sydney: New South Wales Education Portfolio.

Sergiovanni, T. J. (1989). Mystics, neats and scruffies: Informing professional practice in educational administration. Journal of Educational Administration, 27(2), 7-21.

Sirotnik, K. A. \& Burstein, L. (1984). Making sense out of comprehensive schoolbased information systems: Exploring analyses and report methods for school staff. University of California Los Angeles Center for the Study of Evaluation. (ERIC Document Reproduction Service No. ED 263 114)

Sirotnik, K. A. \& Burnstein, L. (1987). Making sense out of comprehensive schoolbased information system: An exploratory investigation. In A. Bank \& R. C. Williams, Information Systems and School Improvement: Inventing the future. New York: Teachers' College Press. (pp. 39-55).

Sirotnik, K. A. \& Oakes, J. (Eds.). (1986). Critical perspectives on the organization and improvement of schooling. Boston: Kluwer-Nijhoff.

Sizer, T. (1984). Horace's compromise. Boston: Houghton-Mifflin.

Telem, M. (1989). Managing information growth and integration in small organisations. Information Processing and Management, 25(4), 443-452.

Turban, E. \& Watkins, P. R. (1986). Integrating expert systems and decision support systems. MIS Quarterly, 10(2), 121-136.

Williams, R. C. \& Bank, A. (1984). Assessing instructional information systems in two districts: The search for impact. Educational Evaluation and Policy Analysis, 6(3), 267-282.

Williams, R. C. \& Bank, A. (1985). School districts in the information society: The emergence of instructional information systems. Administrators Notebook, 31(6).

Wright, P. \& Valbonesi, P. (1985). Microcomputer based school information systems (SIMS) in Alberta junior and senior high schools. Final report. Edmonton, Alberta: Department of Education. (ERIC Document Reproduction Service No. ED 269 893)

Yoo, S. \& Digman, L. (1987). Decision support system: A new tool for strategic management. Long Range Planning, 20(2), 114-124.

Zuboff, S. (1984). In the age of the smart machine. New York: Basic Books.

Authors: Dr John G Hedberg is Associate Professor in Information Technology in Education and Dr Barry Harper a Senior Lecturer, both teach in the Information Technology Program at the Faculty of Education, University of Wollongong, Northfields Avenue, Wollongong, NSW, 2522. Dr Deborah Bloch is Associate Professor, Department of Education, Baruch College, City University of New York, 17 Lexington Avenue, New York, NY 10010, United States of America. This paper is based upon an earlier version presented to the Third Australian Conference on Information Systems, Australian Computer Society, University of Wollongong, October 5-8, 1992.

Please cite as: Hedberg, J. G., Harper, B. and Bloch, D. (1992). Educational information systems: Problems of the small educational organisation. Australian Journal of Educational Technology, 8(2), 132-160. http: / / www.ascilite.org.au/ajet/ ajet8/hedberg.html

Errata: The error in numbering of tables (Table 1 numbering used twice) appears in the original publication. 